Medicine Updates

Faculty of medicine

January 2021, volume 4, issue 4 https://muj.journals.ekb.eg

dean@med.psu.edu.eg

vice_dean_postgraduate@med.psu.edu.eg

DOI: $10.21608 / \mathrm{muj} .2020 .42870 .1031$

\title{
"Neurosurgery in perilous area; is there any role of specialized field hospital in the management of low velocity penetrating head injuries?"
}

Ayman Elsayed Galhom, *Professor of neurosurgery, Port Said, Egypt (Corresponding author).

Abdelrhman Alshawadfy, Lecturer of anesthesia and intensive care Suez canal University.

Mohamed Salah Shater, Assistant lecturer in department of neurosurgery, Faculty of medicine, Suez Canal University.

Amr Said Abuelfadle, Lecturer in department of neurosurgery, Faculty of medicine, Port Said University

\section{$\underline{\underline{\text { Introduction }}}$}

Penetrating head injuries are common in war with relatively high rate of morbidity and mortality. Since world war I, Harvey Cushing was the initial neurosurgeon that endorsed debridement of penetrating head wounds to guard against infection and death. (Cushing, 1918) High velocity missiles are different from low velocity penetrating injuries. (Kaufman et al., 1991) There is many debates about the management of low velocity one. Many centers advocated aggressive debridement to guard against infection with low mortality rate. 
(Loggini et al., 2020) (Smith et al., 2014) (Kazim et al., 2011) However, other report found same or better outcome with minimal or no surgical debridement. (Amirjamshidi et al., 2003)

Minimal intervention could be crucial in areas with low equipment and dangerous medical situation in civil war zone. High velocity gunshot wounds usually need a neuroscience intensive care unit (NICU) due to widespread injuries from high velocity momentum with thermal and kinetic energy conducted to the brain rather than low velocity blast fragment injuries. (Smith et al., 2014)

In Syria civil war, most head injuries occur due to barrel bomb explosives. We studied the management of penetrating head injuries in that area with low equipment facilities and no available NICU.

\section{Material and methods}

\section{Study design and population}

During a period of 6 month of Syrian civil war ( October 2012- March 2013) 30 patients (out of 52 patients) with penetrating head injuries were referred to a 3 different (movable) field hospitals in three different places along Syrian Turkish border.

Inclusion and exclusion criteria

Inclusion criteria included those patients with shrapnel head injury from barrel bomb explosion of any age. Head injuries were categorized according to Glasgow coma scale (GCS) into mild (12-15), moderate (9-12) and sever (3-8) head injuries. The patient should be categorized of mild and moderate head injury with Glasgow coma scale (GCS) ranged from 11 to15, no need for NICU admission, or any other head injury causes like falling from height or motor car accident.

Exclusion criteria was including any patients whom fulfill criteria of NICU admission including; head injury from high velocity gun shots snipers and explosive missiles, or pre management low GCS score. 
Most patients with low GCS was transferred to Turkish border for admission in the NICU. Most patients had low velocity entrance of bomb shrapnel into head scalp. The scalp wound was ranged from less than $1 \mathrm{~cm}$ to more than $5 \mathrm{~cm}$. We noticed that most of injuries from barrel bomb were located in the head, neck, shoulder, and knee as barrel was exploding. Gun shots and explosive missiles had bizarre presentation.

Patients were referred to such early tertiary field hospital care with CT brain. Further laboratory and X-ray investigation were done in the field hospital. After admission, the patient had general anesthesia, less frequently local anesthesia, and wound debridement with removal of shrapnel sometimes under image fluoroscopy when it was inaccessible or deeply seated. Fragmented bone ships were removed during surgery to avoid secondary infection. Wound was sutured by interrupted sutures. Pre-operative installed antibiotic (third generation cephalosporin) and prophylactic antiepileptic (phenytoin) drug for those with brain injury was mounted. After surgery the patient was admitted for 4 to 12 hours before discharge due to limited hospital beds and dangerous situations. In outpatient clinic, we followed patients for wound healing, gradual removal of anti-epileptic drugs, secondary infection, seizure, or development of brain abscess. Conservative management of patients usually was followed by serial CT. Some patients were lost during follow up due to difficult connection between villages or town and movable hospital due to civil war. Cases follow up in some patients extended up to six months postoperative.

\section{$\underline{\underline{\text { Result }}}$}

The mean age for such victims was $26 . \pm 10.1$ and more cases were males. All cases had metal shrapnel fragments. Most clinical presentation was headache $73.3 \%$, due to young age of the patient, no chronic illnesses were reported in the majority of cases $(73.3 \%)$. Table (1) 
All the victims were arrived with local attendant ambulances and were examined within 24 hours after injury. Most patients had clean wound and dressing before arrival and few had bleeding inlet.

GCS upon arrival was fluctuating, and majority was GCS $=15$ (43.3\%). We had no cases of inlet and exit wounds, this could be explained by low velocity nature of the shrapnel injury in high GCS score grade. However, we reported $2(6.7 \%)$ cases with metal fragment crossed the midline and further 3 (10\%) cases had more than one metal in different brain lobes. Frontal lobe is the most frequent affected lobe (53.3\%) and the occipital lobe was the least one (3.3\%). Dominant lobe was more frequently injured (53.3\%) than non-dominant one (46.7\%). Fragmented metals inside the brain were less reported (13.3\%) than the fragmented skull bones (30\%). The most frequent CT finding associated with penetration was contusion, edema and mass effects accounts for (60\%). Table (1)

Surgery (either with local of general anesthesia) was reported in (83.3\%) of cases and $16.7 \%$ was treated conservatively. Hyperosmolar dehydration, antiepileptic drug, and control of intracranial pressure (ICP) were guarded by the anesthetist during anesthesia. The majority of cases had debridement and 5 cases (16.7\%) needed craniotomy flap. Figure (1) One case (3.3\%) needed a decompressive craniectomy. This patient had deterioration of conscious level after surgery that mandated transport to Turkish border. Complication was estimated in this series as follow; infection (10\%), epilepsy (6.7\%), and persistence of preoperative neurological deficit (hemiparesis $10 \%$ and aphasia $6.7 \%$ ). No new added deficit was noticed. Table $(1,2)$ We didn't report complication in conservative cases. Figure (2) To our knowledge, we had no mortality; however, we lost contact with many patients during follow up due to unstable transportation. We had two of our teams (Syrian nurse, and worker) were attacked explosive missile and died throughout the management period.

Surgery was significantly affected by chronic illness $\mathrm{P}=0.04$. Absence of chronic illnesses was associated with favor outcome. More affection of the brain lobes by penetrating metal $(\mathrm{P}=0.001)$, and number of metal fragments inside the 
brain $(\mathrm{P}=0.011)$. Complication after surgery was associated with associated $\mathrm{CT}$ brain finding $(\mathrm{P}=0.005)$. Table (3)

Table (1) Demographic, clinical, and radiological data

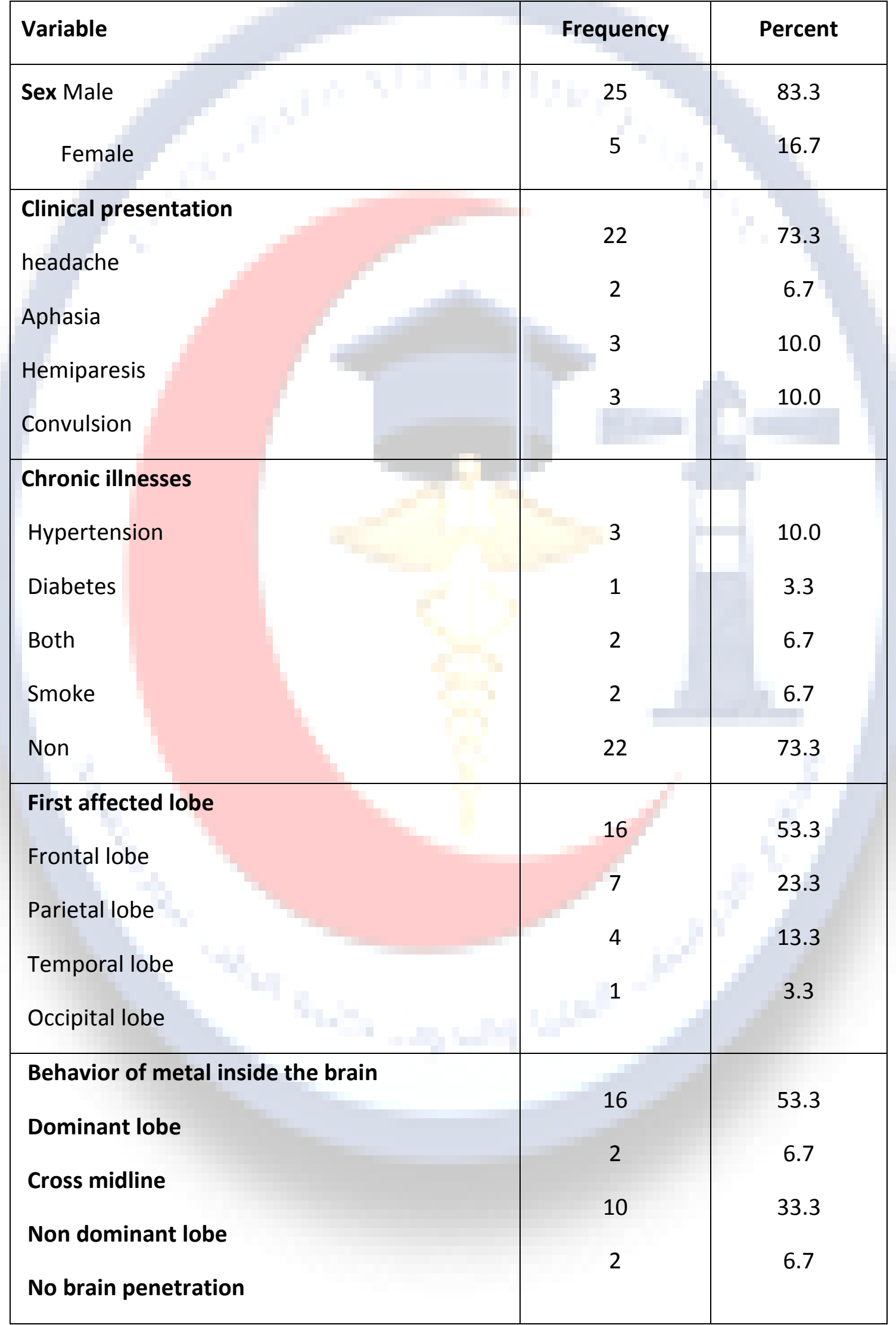




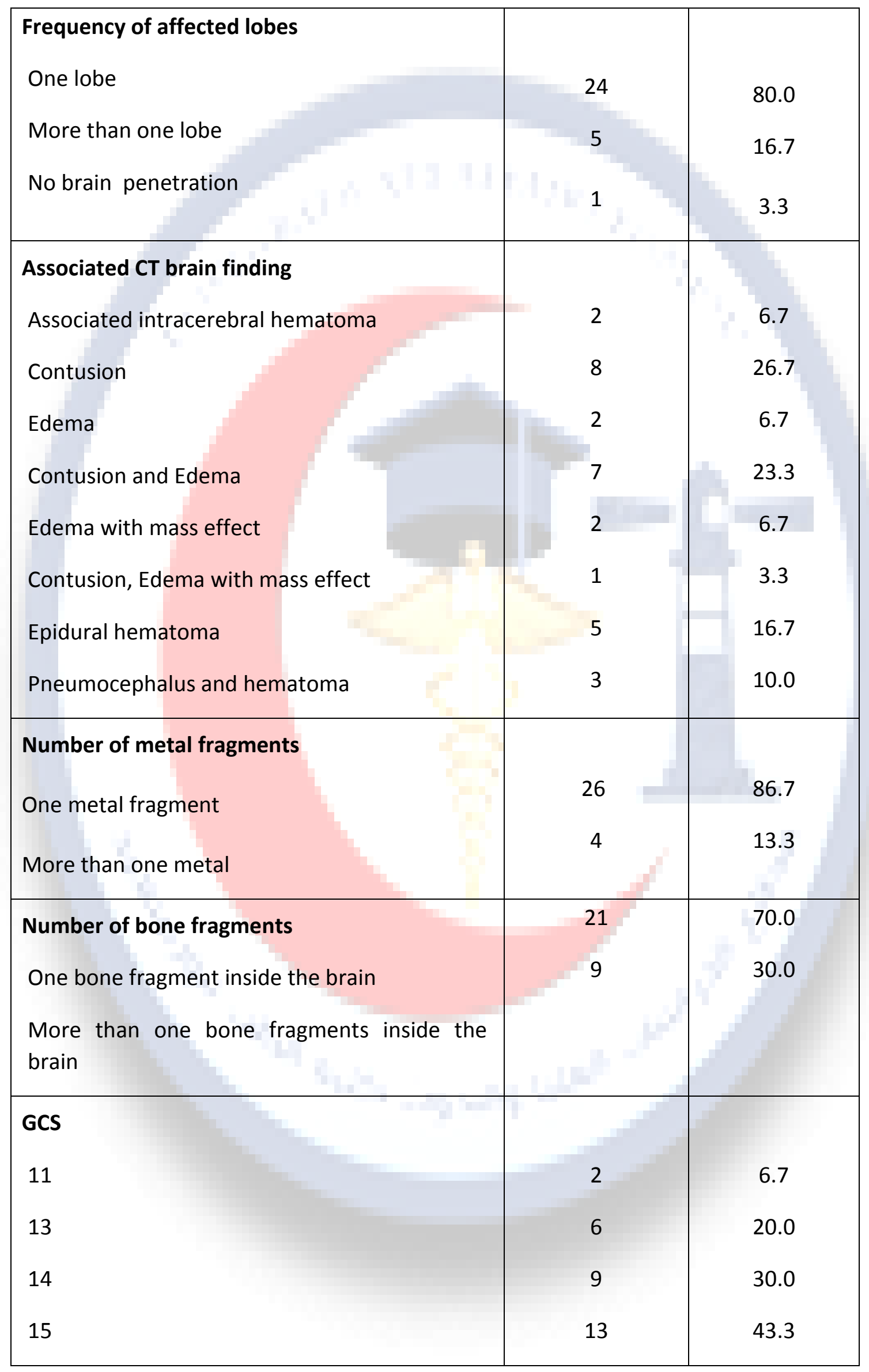




\begin{tabular}{|l|c|c|}
\hline Para-nasal sinus affection & 29 & 96.7 \\
No para-nasal sinus affection & 1 & 3.3 \\
Para-nasal sinus affection & & \\
\hline Complication & 5 & 16.7 \\
Persistent pre-operative neurological deficit & 1 & 3.3 \\
Superficial infection & 2 & 6.7 \\
Deep infection and abscess formation & 2 & 6.7 \\
Epilepsy & 2 & \\
\hline
\end{tabular}

GCS=Glasgow Coma Scale

Table (2) Outcome management of patients with penetrating head injuries

\begin{tabular}{|l|l|l|}
\hline $\begin{array}{l}\text { Management } \\
\text { outcome }\end{array}$ & and & Percent \\
\hline Conservative & 5 & 16.7 \\
\hline Surgery & 25 & 83.3 \\
\hline
\end{tabular}

Table (3) Surgical outcome and complication significance

\begin{tabular}{|l|l|l|l|l|}
\hline \multirow{2}{*}{ Variables } & \multicolumn{2}{|c|}{ Complication } & \multicolumn{2}{c|}{ Surgery } \\
\cline { 2 - 5 } & Chi square & Correlation & Chi square & Correlation \\
\hline Age & 0.41 & 0.504 & 0.67 & 0.68 \\
\hline Sex & 0.53 & 0.92 & 0.42 & 0.36 \\
\hline Chronic illness & 0.19 & 0.38 & $0.04^{*}$ & 0.24 \\
\hline Clinical presentation & 0.29 & 0.40 & 0.25 & 0.95 \\
\hline $\begin{array}{l}\text { Behavior of metal inside } \\
\text { the brain }\end{array}$ & 0.88 & 0.43 & 0.15 & 0.58 \\
\hline
\end{tabular}




\begin{tabular}{|l|l|l|l|l|}
\hline $\begin{array}{l}\text { Frequency of affected } \\
\text { lobes }\end{array}$ & 0.87 & 0.86 & $0.001^{*}$ & 0.65 \\
\hline First affected lobe & 0.56 & 0.58 & 0.14 & 0.82 \\
\hline Number of metal fragment & 0.26 & 0.19 & $0.011^{*}$ & 0.38 \\
\hline Number of bone fragment & 0.74 & 0.45 & 0.32 & 0.27 \\
\hline Associated CT brain finding & $0.005^{*}$ & 0.79 & 0.82 & 0.41 \\
\hline Glasgow Coma Scale & 0.40 & 0.94 & 0.075 & 0.11 \\
\hline
\end{tabular}

* Significant

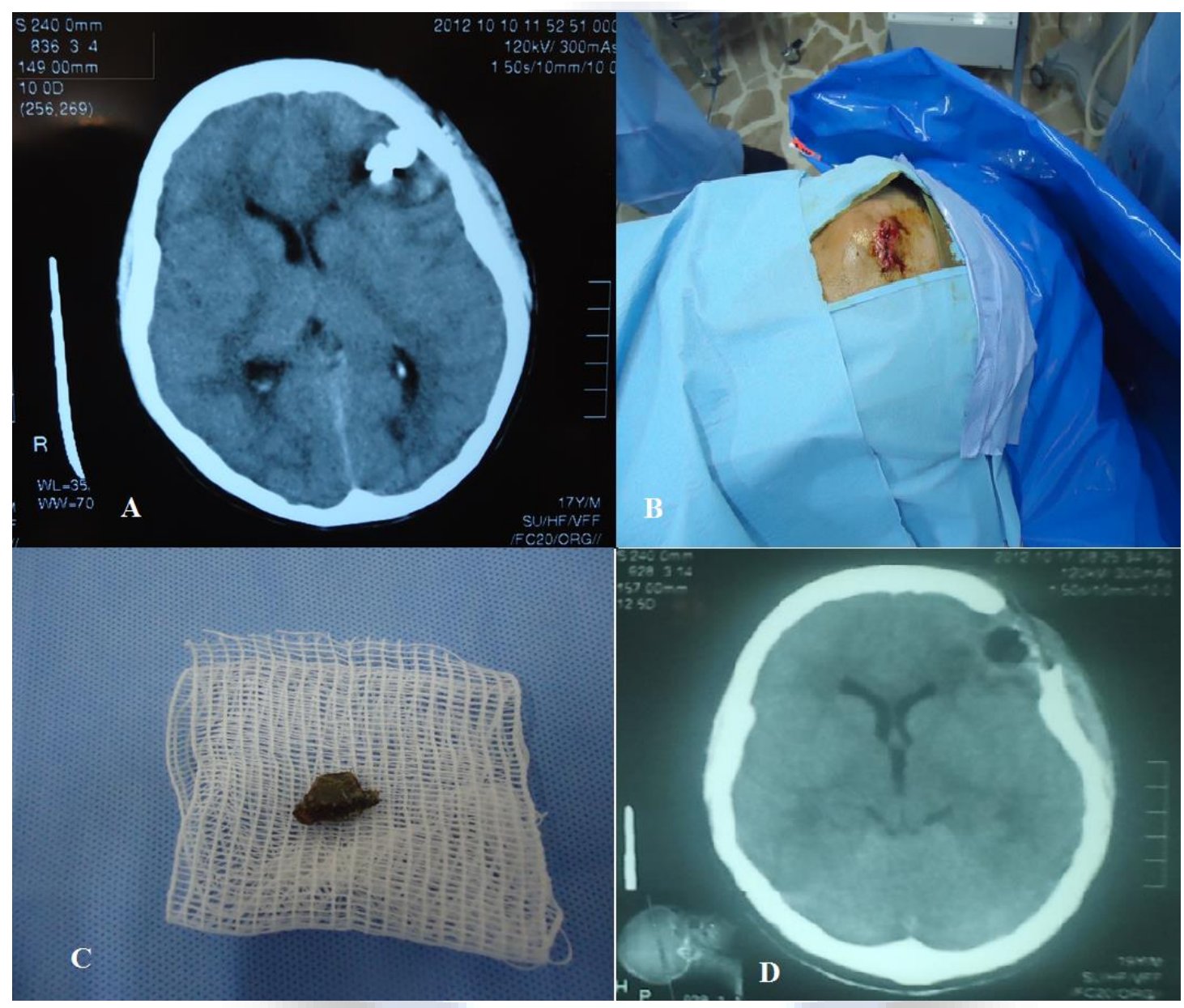

Figure (1) (A) CT brain of a male patient, 21 years old, presented with left frontal metal fragment after barrel bomb explosion. B) Wound exploration after general anesthesia. C) Metal fragment after removal. D) CT brain after metal removal with small skull bone craniectomy and dural repair. 


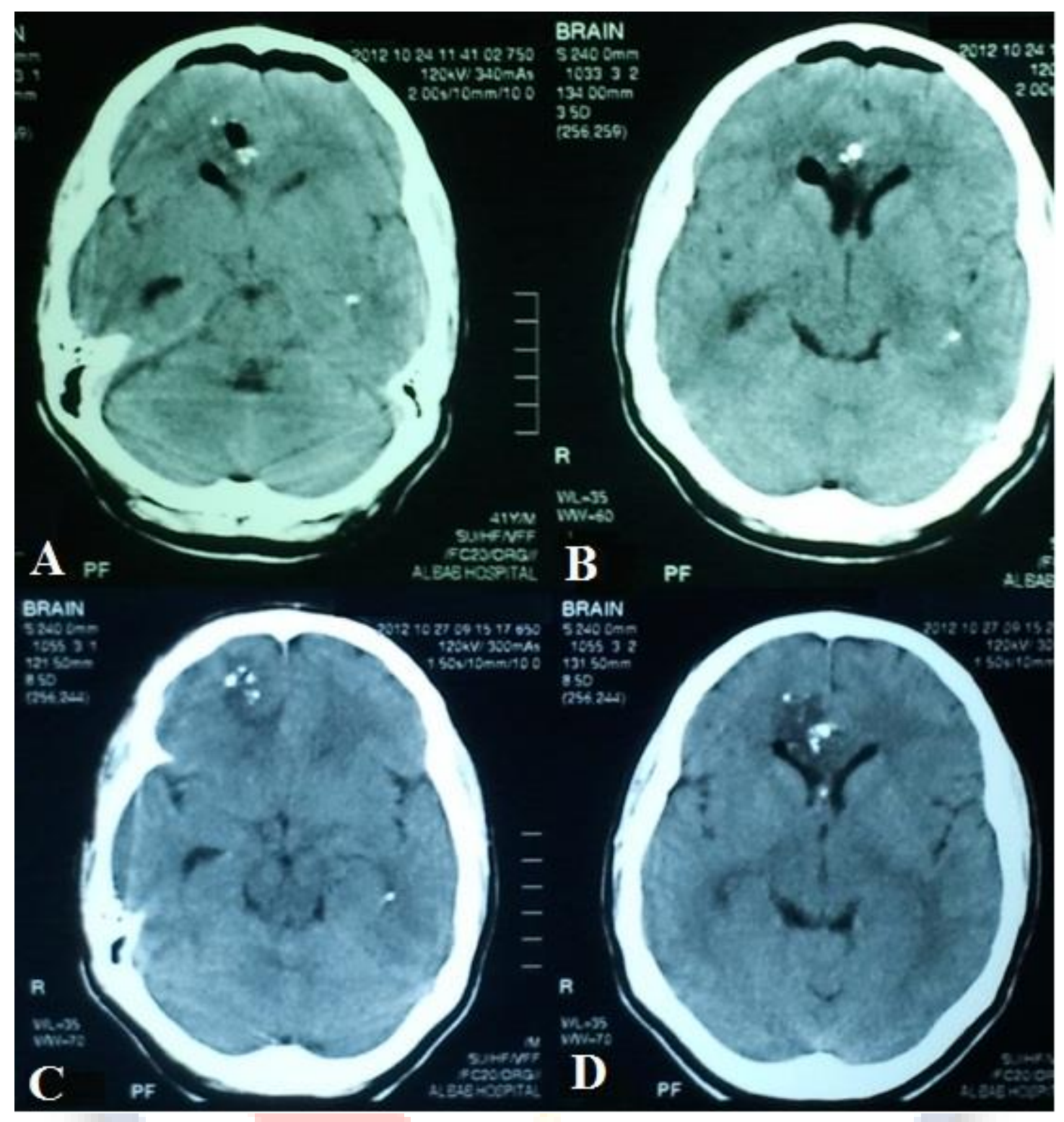

Figure (2) (A) and (B) represented CT brain of a male patient presented with right frontal bone and metal fragments and left temporal metal fragment after barrel bomb explosion associated with pneumocephalus and trapped air inside the lateral ventricle due to fracture base. (C) and (D) represented one week after conservative management with subsidence of air inside the brain and perifocal edema around the fragments.

\section{$\underline{\underline{\text { Discussion }}}$}

Civilian people in war injuries usually presented to emergency department with either gunshot wounds, shrapnel from blast explosive injuries, or missiles explosive injuries. High velocity missiles usually have ominous and profound 
head injury rather than low velocity blast fragments injuries. (Loggini et al., 2020) (Smith JE 2014) Patient can be presented with either poly trauma or isolated head injury. In penetrating head injury, aggressive debridement was reported with increasing incidence of neurological deficit. (Gorji \& Ghadiri, 2001) (Kazemi et al., 2012) Selection of patient with penetrating brain injury for surgery is debatable in literature. (Almogy \& Rivkind, 2006) (Amirjamshidi et al., 2003) Some neurosurgeon takes more conservative approach while other recommended surgical procedures ranges from local to aggressive debridement. (Esposito et al., 2009) (Amirjamshidi et al., 2003) Surgical management for war penetrating head injuries were documented in various from include; simple debridement with removal of metal or bone fragments under local or general anesthesia, local craniotomy and removal of metal and bone fragments, extensive craniotomy for hematoma evacuation, and/ or decompressive craniotomy for decrease ICP. (Maragkos et al., 2018) (Loggini et al., 2020)

Elimination of metal fragment should be done only if it will be accessible to the surgeon without brain damage. (Kazemi et al., 2012) Deep brain exploration carries a high risk of morbidity as metal fragment may drifted into the cerebral vessels causes vascular injuries, or cerebrospinal fluid (CSF) contamination. (Van Wyck, 2015) In this series, surgical outcome was affected by the number of the affected brain lobes by penetrating metals $(\mathrm{P}=0.001)$ and number of metal fragments inside the brain $(\mathrm{P}=0.011)$. Such risk makes some neurosurgeon to become less aggressive during surgical debridement with more prophylaxis antibiotic administration. (Kazim et al., 2011) In our report, surgery was stated in $(83.3 \%)$ of cases and $16.7 \%$ was treated conservatively. The majority of the surgical cases had debridement and 5 cases $(16.7 \%)$ needed craniotomy flap and one case (3.3\%) required a decompressive craniectomy. Clinical finding especially GCS is cardinal feature for surgery in injured patient. (Folkerson et al., 2018 ) GCS is fundamental feature in management of our cases. The management strategies in this series was limited surgical maneuver attributed to many factors including; shortage of neuroscience ICU and patient 
selection (GCS $\geq 11$ ), the majority of cases was GCS 15 (43.3\%), and no single reported case presented with exit wounds due to the low velocity explosive nature of the selected cases. In these series, Surgery was significantly affected by pre hospital existence of chronic illness $(\mathrm{P}=0.04)$. Number of brain lobes affected by penetrating metal $(\mathrm{P}=0.001)$, and number of metal fragments inside the brain $(\mathrm{P}=0.011)$.

Additional important influence for surgical maneuver is CT finding. It is not only and indicator for surgery and management of penetrating head injuries, but also it could affect the prognosis for such patients. (Folkerson et al., 2018) The most frequent CT finding in these series was the association of fragments with contusion, edema and mass effects (60\%). CT brain finding reported in literature with penetrating head injuries and carries bad prognosis including; multiple brain injuries, intra-ventricular or subarachnoid bleeding, and obliteration of the basal cistern from herniation syndrome. (Almogy \& Rivkind, 2006) (Folkerson et al., 2018) (Smith et al., 2014) (Maragkos et al., 2018) However, complication after surgery in this report was statistically significant associated with CT brain finding (0.005).

Before surgeries, and due to limited sources, we didn't have intracranial pressure monitoring or NICU. In these field hospitals, we used hyperosmolar therapy to decrease suspected rising intracranial pressure from associated brain edema and mass effect.

In penetrating head injury with explosive missile, the infection rate was reported in war from 6\% to $15 \%$ (Amirjamshidi et al., 2003) (Loggini et al., 2020) (Van Wyck, 2015) (Smith et al., 2014) (Kazim et al., 2011) (Maragkos et al., 2018) comparable to (10\%) in our result in field hospital with limited resources. Loggini A, et al had reported low infection rate 5\% with conservative or minimal surgical intervention. (Loggini et al., 2020) Infection in penetrating head injury is including superficial and deep wound infection, meningitis and encephalitis, and development of brain abscess. (Esposito et al., 2009) According 
to previous statement, prophylactic antibiotics are initiated as an early treatment upon patient admission whether he was going for surgical or conservative management. Prophylactic antibiotics is essential in such injuries especially in that metal penetrating with contamination the skull, or penetrating unhealthy Para nasal sinus or oral cavity. (Bolatkale \& Acara, 2019)

A second common complication in penetrating head injury is seizure. Many series describe high incidence of seizure including Iraq -Iran war 75\%, Vietnam 53\%, Korea 36\%. (Salazar et al., 1985) (Amirjamshidi et al., 2003) (Smith et al., 2014) In this series, seizure was reported in $(6.7 \%)$ of cases. Seizure is common during follow up in cases that developed encephalomalacia or those with retained metal inside the brain. (Salazar et al., 1985) (Richmond \& Lemaire, 2008) This stage needs long term follow up which is not available in this study. Our seizure report number could be anticipated to increase as we had $6.7 \%$ of cases with metal cross midline, $10 \%$ had more than one metal in different brain lobes, and fragmented skull bones inside the brain was reported in $30 \%$. Furthermore, Frontal lobe is the most frequent penetrating lobe $(53.3 \%)$ with metal. However, no available statistical data could be verifying such finding.

We had no mortality in these series; however, we lost contact with many patients during follow up due to unstable transportation. Mortality rate is depending on GCS, and type of penetrating injury. Mortality rate ranges from 17-24\% in GCS 3-8. (Weisbrod et al., 2012) A high velocity gunshot injury had a higher mortality rate compare to low velocity blast fragment. (Smith et al., 2014)

This study has some limitations including low available medical supplies due to working in changeable field hospitals to increase spectrum of penetrating head injuries patient management. Short time follows up of the patients which ranges from 12 hours to 1 week in some patients due to dangerous travel. However, our result suggested that movable field hospital can be valid in the 
management of a spectrum of patient with low velocity explosive metal head injuries.

\section{Conclusion}

Selection of treatment modality either conservative or surgical for patients with penetrating brain injury is debatable in literature. Surgical outcome can be affected by number of factors including number of the affected brain lobes by penetrating metals, number of metal and bone fragments inside the brain. GCS, pre surgical existence of chronic illness, and CT brain finding can affect the patient management and prognosis. Field hospital could be valid in the management of a spectrum of patient with low velocity explosive metal head injuries.

\section{$\underline{\underline{\text { References }}}$}

- Almogy G, Rivkind AI. Surgical lessons learned from suicide bombing attacks. J Am Coll Surg, 2006: 202:313-9.

- Amirjamshidi A, Abbassioun K, Rahmat H. Minimal Debridement or Simple Wound Closure as the Only Surgical Treatment in War Victims with Low-Velocity Penetrating Head Injury indications and management protocol based on more than 8 years follow up of 99 cases from Iran-Iraq conflict. Surg Neurol, 2003: 60:105-11.

- Bolatkale M, Acara AC. The intracranial number of foreign bodies as a predictor of mortality after penetrating brain injury. American Journal of Emergency Medicine, 2019: 37: 433-438.

- Cushing, Henry. A study of a series of wounds involving the brain and its enveloping structures. Br J Surg, 1918: 5: 558-684.

- Esposito DP, Walker JP. Contemporary management of penetrating brain injury. Neurosurg Q, 2009: 19:249-54.

- Folkerson LE, Sloan D, Davis E, Kitagawa RS, Cotton BA, Holcomb JB, et al. Coagulopathy as a predictor of mortality after penetrating traumatic brain injury. Am J Emerg Med, 2018 : 36(1):38-42. 
- Gorji A, Ghadiri KM. History of epilepsy in medieval Iranian medicine. Neuroscience and Biobehavioral Reviews, 2001: 25:455-61.

- Kaufman HH, Schwab K, Salazar AM. national survey of neurosurgical care for penetrating head injury. Surg Neurol 1991, 1991: 36:370-7.

- Kazemi H, Fesharaki SH, Razaghi S, Najafi M. Intractable epilepsy and craniocerebral trauma: analysis of 163 patients with blunt and penetrating head injuries sustained in war. Injury, Int. J. Care Injured, 2012: 43: 21325.

- Kazim SF, Shamim MS, Tahir MZ, Enam SA, Waheed S. Management of penetrating brain injury. J Emerg Trauma Shock, 2011: 4:395-402.

- Loggini A, Vasenina VI, Mansour A, Das P, Horowitz PM. Management of civilians with penetrating brain injury: A systematic review. Journal of Critical Care, 2020: 56:159-166.

- Maragkos GA, Papavassiliou E, Stippler M, Filippidis AS. Civilian gunshot wounds to the head: prognostic factors affecting mortality: metaanalysis of 1774 patients. J Neurotrauma, 2018: 35(22):2605-14.

- Richmond TS, Lemaire J. Years of life lost because of gunshot injury to the brain and spinal cord. Am J Phys Rehabil, 2008: 87(8):609-15.

- Salazar AM, Jabbari B, Vance SC, Grafman J, Amin D, Dillon JD. Epilepsy after penetrating head injury. I. Clinical correlates: a report of the Vietnam Head Injury Study. Neurology , 1985: 35:1406-14.

- Smith JE, Kehoe A, Harrisson SE, Russell R, Midwinter M. Outcome of penetrating intracranial injuries in a military setting. Injury, Int. J. Care Injured, 2014: 45: 874-878.

- Van Wyck, DW. Penetrating traumatic brain injury: a review of current evaluation and management concepts. Neurol Neurophysiol, 2015: 6:33642.

- Weisbrod AB, Rodriguez C, Bell R, Neal C, Armonda R, Dorlac W, et al. Longterm outcomes of combat casualties sustaining penetrating traumatic brain injury. J Trauma, 2012: 73:1525-30. 